Vol. I, Part 4 will be published in December, 1960.

It will include the following papers:

Asymptotic formulae for the solutions of linear second-order differential equations with a large parameter. . . . . . . . . . . . R. C. THORNE

The existence of a parametric surface integral. . J. H. MichaEL Scales of functions. . . . . . . . . P. Erdös, C. A. Rogers, S. J. TAYLOR

The expansion of functions in ultraspherical polynomials. . . . . . . . . . . . . . D. ElliotT

Mahler's matrices . . . . . . . . . . . D. H. LeHMER

Expectation values of operators on the quasichemical equilibrium theory . . . . . . . . J. M. BLATT

The survival of a mutant gene under selection. II P. A. P. MORAN Acceleration and the "clock-paradox". . . . . . C. A. HuRsT 
Prof. L. V. Kantorovich and V. I, KrYLOV

\title{
APPROXIMATE METHODS OF HIGHER ANALYSIS
}

\author{
Translated from the fourth Russian edition by Curtis D. Benster. \\ $1959 \mathrm{XVI}+681 \mathrm{pp}$. \\ Cloth bound Dfl. 64.-
}

A systematic development of highly effective methods for approximate solution of the boundary value problems of classical mathematical physics. Presentation and point of view of the material are quite unique.

"The work has already obtained a great succes in the whole Soviet Union and its utility appears all the more evident in view of the ample application of approximate metbods in the work of the technical and scientific institutes. The book is particularly important for draning the attention of a rich calegory of interested readers to the approximate solution of the integral equations of Fredholm; the variable methods; the conformal transformation of regions; the solution of the fundamental problems and the application of Schwarz's method."

(Bollettino Internazionale delle Opere Scientifiche)

Pure and applied mathematicians will find the book a source of results and ideas, useful for direct applications as well as stimulating for further research.

Research and practical engineers will find new and less well-known numerical answers to specific ptoblems without having to digest their complete theoretical background.

Theoretical physicists and chemists will find this book a link between their mathematical training and physical reality.

An indispensable tool for every careful investigator in the field of numerical analysis and for everyone concerned with numcrical solution of problems in mechanics, electro-dynamics etc.

Prof. A. V. POGORELOv - Kharkov State University

\section{DIFFERENTIAL GEOMETRY}

Translated from the first Russian edition by Leo F. Boron.

1959 IX $+171 \mathrm{pp}$.

Df. 14.50 , cloth bound Df. 16.50

A thorough study of the properties of curves and surfaces and their families. A large amount of factual material has been relegated to exercises and problems at the end of each chapter.

$$
\begin{gathered}
\text { Order } \\
\text { through your local bookseller } \\
\text { or direct from }
\end{gathered}
$$

P. Noordhoff Ltd., Publishers

P. O. B. 39, Groningen, The Netherlands 
Prof. V. V. NovozHiLov - University of Leningraa

\section{THE THEORY OF THIN SHELLS}

Translated from the Russian by P. G. Lowe, Sydney University Edited by J. R. M. Radok.

1959 XVI+372 pp. +Indexes

Cloth bound Dfl. 36.-

This book elucidates the problems, inherent to the linear theory of thin shells, from a unified point of view which essentially consists of the wide utilization of complex transformations.

It contains four parts:

The general theory of thin shells - The membrane theory - Analysis of cylindrical shells - Shells of revolution.

"Summing up, Novozhilov's book is an important addition to the available literature on shell theory, and the editor, translator and publishers are to be congratulated on their success in making this work easily accessible; it is hardly noticeable that the present book is a translation, and the production of the book is up to the high standards of the publishers, at a price which is moderate in present circumstances."

(W. T. Koiter in Nieuw Archief voor Wiskunde, March 1960)

Prof. Dr. V. HLAvaty - Indiana University

\section{GEOMETRY OF EINSTEIN'S UNIFIED FIELD THEORY}

Providing a detailed geometrical background for physical applications of this theory.

$1958 \mathrm{XXXII}+341 \mathrm{pp}$.

Cloth bound Df. 37.--

"The value to be attributed to this book depends on the importance to be attached to 1) Einstein's general and generalized theory, 2) formal tensor analytic methods . . . . it must be admitted that the author has done an excellent job, that he knows to handle Schouten's formalism in a very skilful way, and that he has shown it to be a perfect tool for handling even these subtle and intricate questions. From the point of view of tensor analysis as such Hlavaty's book deserves high praise and strong recommendation."

(D. van Dantzig in Nieuw Archief voor Wiskunde, Nov. '59)

\section{Order \\ through your local bookseller or direct from}

P. Noordhoff Ltd., Publishers

P. O. B. 39, Groningen, The Netherlands 